DOI 10.37882/2223-2982.2021.05-3.03

\title{
ТВОРЧЕСКИЕ ЗАДАНИЯ, ФОРМИРУЮЩИЕ, РАЗВИВАЮЩИЕ И ЗАКРЕПЛЯЮЩИЕ ЯЗЫКОВЫЕ И КОММУНИКАТИВНЫЕ НАВЫКИ НА УРОКАХ ИНОСТРАННОГО ЯЗЫКА
}

\section{CREATIVE TASKS THAT FORM, DEVELOP AND CONSOLIDATE LANGUAGE AND COMMUNICATION SKILLS IN FOREIGN LANGUAGE LESSONS}

I. Belyaeva

E. Samorodova M. Ogorodov

Summary: In this article, the authors consider creative tasks as a tool for developing foreign language communication skills and introduce school teachers and university teachers to the types and types of creative tasks that have proven their effectiveness in foreign language classes with MGIMO students.

Keywords: creative tasks, Singapore methodology, educational comic, idea generator.
Беляева Ирина Георгиевна

к.филол.н., старший преподаватель, ФГАОУ ВО «Московский государственный институт международных отношений (университет) Министерства иностранных дел Российской Федерации» i.beliaeva@inno.mgimo.ru

Самородова Екатерина Александровна к.ю.н, дочент, ФГАОУ ВО «Московский государственный институт международных отношений (университет) Министерства иностранных дел Российской Федерации» e.samorodova@inno.mgimo.ru

Огородов Михаил Константинович к.филол.н., доцент, ФГАОУВО «Московский государственный институт международных отношений (университет) Министерства иностранных дел

Российской Федерации» mkogo@mgimo.ru

Аннотация: В данной статьи авторы рассматривают творческие задания как инструмент развития иноязычных коммуникативных навыков и знакомят учителей школ и преподавателей вузов с видами и типами творческих заданий, которые доказали свою эффективность на занятиях по иностранному языку со студентами МГИМО.

Ключевые слова: творческие задания, сингапурская методика, образовательный комикс, генератор идей.

учащиеся должны совместить индивидуальные способности с развиваемыми преподавателем навыками.

Творческие задания на уроках иностранного языка могут носить облигаторный и факультативный характер. Облигаторные творческие задания направлены на формирование, развитие и закрепление у всех учащихся языковых и коммуникативных навыков путём создания нестандартных учебных ситуаций, решить которые может в той или иной степени любой учащийся, что в своей совокупности обеспечивает формирование иноязычной компетенции каждого обучающегося.

Факультативные творческие задания направлены не столько на формирование языкового и коммуникативного навыков, сколько являются средством, способствующим преодолению изучающими иностранный язык трудностей, возникающих на их пути или применения развиваемых навыков в сферах, требующих особого таланта обучающихся. В основе данной статьи лежит анализ научной литературы в сфере творческой деятельности учащихся на занятиях по иностранному языку 
и личный многолетний опыт педагогической деятельности авторов данной статьи.

Творческие задания рассматриваются в педагогической литературе как важный компонент уроков иностранного языка, способствующий развитию речи. Это связано в первую очередь со спонтанным, творческим использованием языка в речи [1], [4], потребностью человека в инновациях для порождения новых смыслов [7],[8] способностью творческих заданий мотивировать учащихся [3] и развивать отдельные навыки [5], [2].

В ходе работы использовались метод системного анализа, сравнительный и сопоставительный методы.

Не все учащиеся способны создать приёмы, способствующие преодолению языковых барьеров. Чаще всего такими барьерами становятся сложности, возникающие при усвоении лексико-грамматического материала, и связаны они зачастую с процессом запоминания и удержания в памяти информации на длительный срок. Для их более легкого и успешного преодоления изучающим иностранный язык можно предложить создать способы восприятия учебного материала, облегчающие процесс запоминания. В основном обучающиеся прибегают к методам мнемотехники.

При изучении лексико-грамматического материала преподаватели часто самостоятельно предлагают студентам те приёмы мнемотехники, которые способствуют запоминанию изучаемых явлений. Наиболее эффективными и популярными являются рифмовки для запоминания лексических единиц и грамматических правил, которые существую далеко не ко всем лексико-грамматическим особенностям немецкого языка. И иногда предложение студентам самим найти наиболее оптимальный способ запоминания того или иного грамматического явления даёт неожиданные результаты с интересными решениями.

Анастасия Колмогорова, студентка 1 курса МГИМО 2017/ 2018 уч.года предложила следующий способ запоминания предлогов с Akkusativ:

\section{Entlang, bis,}

für, gegen, ohne

durch und um die schöne Sonne!

Основную группу творческих заданий составляют облигаторные задания, направленные на развитие и автоматизацию таких компонентов языковых и коммуникативных навыков как фонетических, лексических, грамматических.

Развитию фонетических навыков способствуют фонетические конкурсы, публичные выступления, создание аудиокниг и работа в качестве диктора при создании подкастов.

Лексико-грамматические творческие задания направлены преимущественно на различную степень визуализации информации.

Некоторые учащиеся используют mind map как средство визуализации содержания текста, представляя информацию не в вербальном формате, а используя символы. Рисунок 1 представляет собой mind map по теме «Мой рабочий день».

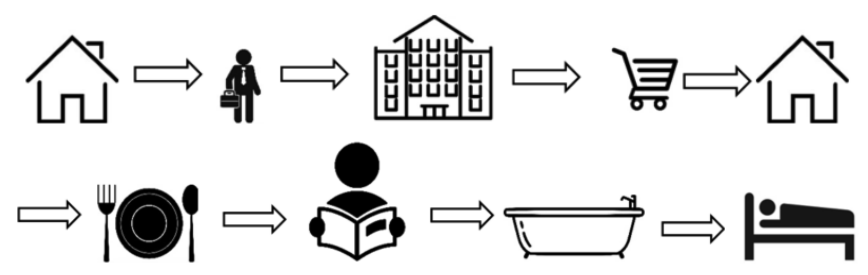

Рис. 1. mind map «Мой рабочий день»

Для активизации лексики в устной / письменной монологической и устной диалогической речи успешно применяются элементы сингапурской методики, базирующиеся на творческом потенциале учащихся. Учащимся могут быть предложены следующие задания:

а) Придумайте рассказ, историю, используя вокабуляр, подлежащий усвоению. Коллективное сочинение осуществляется при помощи структуры All Write Round Robin - когда учащиеся по очереди зачитывают по предложению, а все остальные записывают новые идеи на своих листках. Время выполнения ограниченно количеством имеющихся в таблице строк и лексических единиц в них.

b) Придумайте рассказ, историю, используя вокабуляр, подлежащий усвоению. Коллективное сочинение осуществляется при помощи структуры Round Table, когда обучающиеся по очереди выполняют письменную работу по кругу на одном для всей команды листе бумаги. Все предложения связаны между собой по смыслу. Время выполнения ограниченно количеством имеющихся в таблице строк и лексических единиц в них.

с) Составьте диалог с опорой на вокабуляр, подлежащий усвоению, используя обучающую структуру Inside-Outside Circle. Для ведения диалога учащиеся формируют внутренний (задаёт вопрос) и внешний (отвечает на вопрос) круги, перемещение по кругу даёт возможность пообщаться с разными партнёрами. После завершения круга задача, поставленная перед внешним и внутренним кругами, меняется: Внутренний (отвечает на вопрос), а вешний (задаёт вопрос). Диалог с каждым из партнёров может ограничиться как одним вопросом, так стать полноценным завершённым диалогом.

1 Использованы символы: уoutube.com (Projekt Dom); Vector Stock; Vector ICON; Semalt.com; Ru.dreamstime.com; Market.yandex 
Облигаторные творческие задания наиболее часто используются преподавателями в рамках игрового метода и ИКТ.

В данной статье игровой метод рассматривается как платформа для реализации творческого потенциала учащихся, способствующего развитию в первую очередь языковых навыков обучающихся, а затем их переходу в коммуникативные. Игровой метод обучения иностранному языку включает в себя большое количество их типов: ролевые, деловые. Они могут быть направлены на формирование фонетического, лексического, грамматического навыков. Зачастую такие игры предлагаются преподавателями иностранного языка как готовый продукт. Но создание самих игр школьниками или студентами может принести ещё больше пользы при работе над развитием того или иного навыка.

Для изучения счёта и алфавита преподаватель может предложить ученикам сделать лото. Другой игрой, способствующей запоминанию счёта и алфавита, может стать настольная игра, состоящая из карточек, фишек и кубиков. Изучающие иностранный язык изготавливают карточки, на которых пишут буквы или цифры, раскладывают их по кругу в произвольном порядке и начинают ходить по очереди, начиная с буквы «А» или цифры «один». Ходы совершаются после броска кубика в соответствии с количеством ходов и осуществляются или в алфавитном порядке, или в соответствии с порядком цифр. Если игрок без ошибок достигает нужной буквы или цифры, то он забирает её себе. Побеждает тот, кто наберёт больше букв или цифр.

Лексический материал хорошо закрепляется при помощи тематических игр Мето. Отличаются они как правило различным способом презентации пар. Пары могут состоять из картинки и её лексического соответствия, на начальном этапе это могут быть картинки, разрезанные пополам с разрезанными на два слога подписями к ним. Тренировать лексику можно при помощи разрезанных пополам изображений предметов, каждая половинка которых содержит половину лексемы. В таком случае карточки складываются в колоду, игроки по очереди тянут карточки, называя предмет. Карточку получает игрок, у кого есть вторая половинка. Побеждает тот, у кого больше карточек.

Благодатной почвой для творческих заданий являются средства ИКт. Создание учебных роликов при помощи программ Intro Maker или Film Maker Pro способствует более прочному усвоению знаний у его создателя и облегчают восприятие материала другими учащимися. Созданный ролик для закрепления трёх форм глагола (рис 2.), особенностей их спряжения (рис. 3) показал хороший результат с точки зрения качества усвоения учебного материала. Ученики имели возможность мно- гократно просматривать его в течении дня на своих мобильных телефонах.

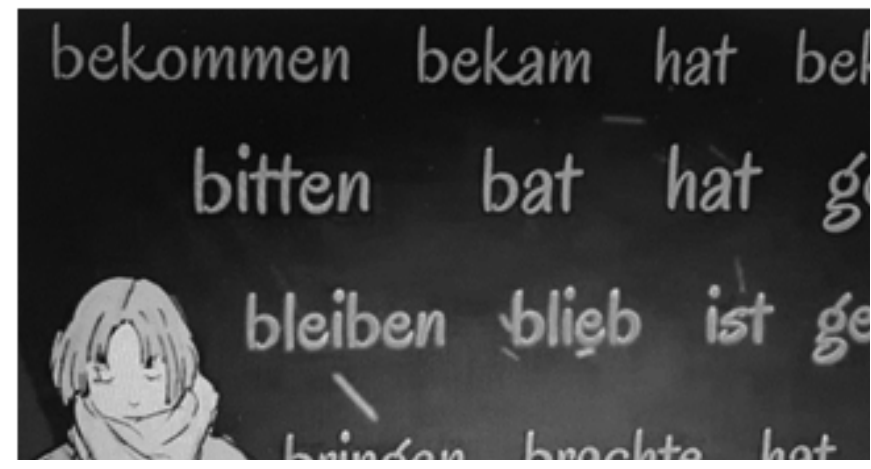

Рис. 2. Фрагмент ролика для заучивания 3 основных форм глагола, созданный при помощи Film Maker Pro

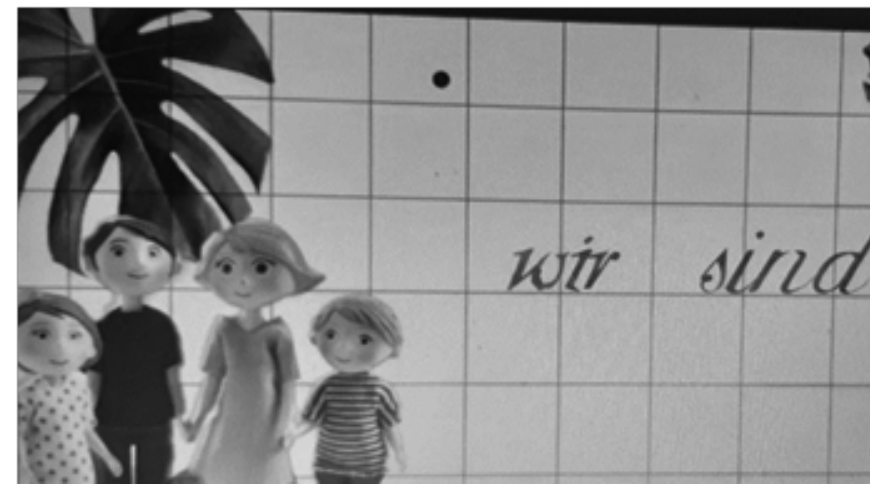

Рис. 3. Фрагмент ролика для заучивания спряжения глагола sein, созданный при помощи Film Maker Pro

Все изучаемые грамматические темы могут быть распределены между обучающимися для создания учебных роликов, что вовлечёт в процесс создания всех учащихся и создаст наглядную учебную базу.

Большой потенциал имеют обучающие мультфильмы, созданные руками изучающих немецкий язык. Благодаря простым в использовании программам данный вид деятельности стал доступен все желающим. Работа над созданием мультфильмов наиболее эффективна, когда она организована как групповой вид деятельности. В этом случае она охватывает максимальное количество учащихся. Создание мультфильма для закрепления лексического или грамматического материала требует создания сценария, его тщательной проработки с лингвистической точки зрения. Также интересным видом деятельности с точки зрения развития коммуникативных лингвистических компетенция является создание мультфильмов к произведениям по домашнему чтению.

Если создания мультфильма требует, как правило регистрации, а доступ к таким программам преимущественно платный, то создание комиксов требует минимального знания компьютерных программ на уровне 
пользователя, регистрация не всегда обязательна и создание комиксов с технической точки зрения является более простым в отличии от создания мультфильмов. Достаточно просто самостоятельно создать комиксы при помощи генератора комиксов http://1001mem.ru/ create_comics, который очень прост в управлении, имеет в арсенале большое количество заготовок, кроме того, есть возможность самостоятельно рисовать. Ещё более простым является генерирование комиксов на сайте http://www.wittycomics.com/ с широким выбором уже готовых рисунков. Комиксы, как и мультфильмы могут использоваться в обучении иностранному языку. При этом необходимо выделить два типа комиксов - созданных преподавателями для учащихся и созданных самими учениками. Наиболее популярны комиксы, созданные педагогическими работниками в обучающих целях и опубликованные в учебных пособиях. Например, в учебном пособие Halb sieben vor dem Kino [6], все учебные тексты представлены в виде комиксов. Менее популярны образовательные комиксы, созданные учениками, хотя они несут в себе достаточно большой педагогический потенциал. Создавая комиксы, учащиеся могут тренировать диалогическую речь, закреплять изученный лексический материал, моделируя реальные ситуации общения, а также создавать серию комиксов на базе домашнего чтения, показывая преподавателю знание и понимание содержание прочитанного, а также закрепляя лексико-грамматический материал. Комиксы по домашнему чтению могут создаваться как в качестве индивидуальной работы каждого учащегося, так и в качестве групповой проекторной работы. Работа над самостоятельным созданием иноязычного текста, его визуализация способствует более прочному и длительному усвоению знаний.

Проблемный метод обучения - это не только дискуссия, дилемма. кейс-стади, круглый стол, Peer review, но и любой вид деятельности, связанный с решением конкретной проблемы. Творческие задания обычно нацелены на решение определённой творческой задачи. Запоминание лексического минимума всегда лучше протекает в контексте, а ещё эффективней, когда контекст создаётся самими учениками. Одним из эффективных заданий, которое способствует запоминанию лексем это составление рассказа с этими словами. Помимо собственно усвоения лексики развивается также коммуникативный навык.
Интересным видом деятельности для развития коммуникативного навыка является работа с поэтическими текстами. Достаточно популярным видом деятельности стало создание синквейнов, для которых важным является не ритм, а содержание, заключённое в определённую форму.

Типичный синквейн представляет собой пять строк. Первая строка это как правило существительное; вторая строка - прилагательное или причастие, характеризующее это существительное; в третьей строке сообщается о том, что совершается; в четвёртой строке автор выражает в четырёх словах личное отношение к теме; в пятой строке одним словом подводится итог:

Der Frühling.

Sonnig, zart.

Blüht, grünt, riecht.

Webt bunte, prachtvolle Kleider

Erwachen.

Помимо синквейнов доступно для всех учащихся задание, заключающееся в завершении стихотворения, для которого важен ритм. Самостоятельное завершение стихотворений, подчинённых определённому ритму, способствует более прочному удержанию лексических единиц. На первоначальном этапе в стихотворении могут быть указаны, например, глаголы и последнее слово каждой стихотворной строки, а на последующих этапах только последнее слово каждой из стихотворных строк.

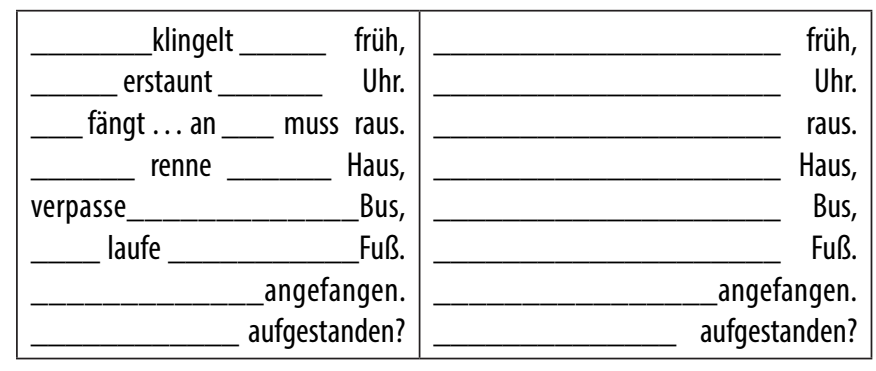

Создание разнообразных видов творческих заданий для развития иноязычной компетенции учащихся является не простой задачей преподавателя. Новый виток создания творческих заданий может быть создан благодаря развитию генераторов идей и освоений их преподавателями, например таких, как https://kreamozg.ru/ programma.html, http://blog.sockenzombie.de/zeichnerideen-generator/.

\section{ЛИТЕРАТУРА}

1. Гафарова, Асия Султановна. Опыт использования платформы Zоот при обучении немецкому языку как второму иностранному (на материале учебного пособия "im Klartext") / А.С. Гафарова, 0.С. Хосаинова // Иностранные языки в школе. - 2020. - № 10. - С. $68-74$.

2. Мюллер Ю.Э. Bildung und Gebrauch des Perfekts. Eine Übungsreihe zum Thema «Winterferien» / Ю.Э.Мюллер, О.В.Принципалова, Н.Е.Меркиш // Иностранные языки в школе. — 2019. — №1. — C. 32-38. 
3. Avila, H.A. (2015). Creativity in the English class: Activities to promote EFL learning. HOW, 22(2), 91-103. http://dx.doi.org/10.19183/how.22.2.141.

4. Becker C. \& Roos J. (2016) An approach to creative speaking activities in the young learners' classroom, Education Inquiry, 7:1, D0I: 10.3402/edui.v7.27613

5. Pishghadam, Reza \& Fatemh, Javdan \& Mehr.. (2011). Learner Creativity and Performance in Written Narrative Tasks. World Journal of Education. 1. 10.5430/wje. v1n2p115.

6. Plein, Frank; Breslauer, Christine (2019): Halb sieben vor dem Kino. Ein Comic-Sprachkurs für Anfänger. Stuttgart: PONS.

7. Tan Bee Tin, Towards creativity in ELT: the need to say something new, ELT Journal, Volume 67, Issue 4, October 2013, Pages 385-397, https://doi.org/10.1093/elt/ cct022

8. Xylander, C. von. (2020). A(I)gora: The Mindscape. Technology and Language, 1(1), 115-125. https://doi.org/10.48417/TECHNOLANG.2020.01.23

(о Беляева Ирина Георгиевна (i.beliaeva@inno.mgimo.ru), Самородова Екатерина Александровна (e.samorodova@inno.mgimo.ru), Огородов Михаил Константинович (mkogo@mgimo.ru).

Журнал «Современная наука: актуальные проблемы теории и практики»

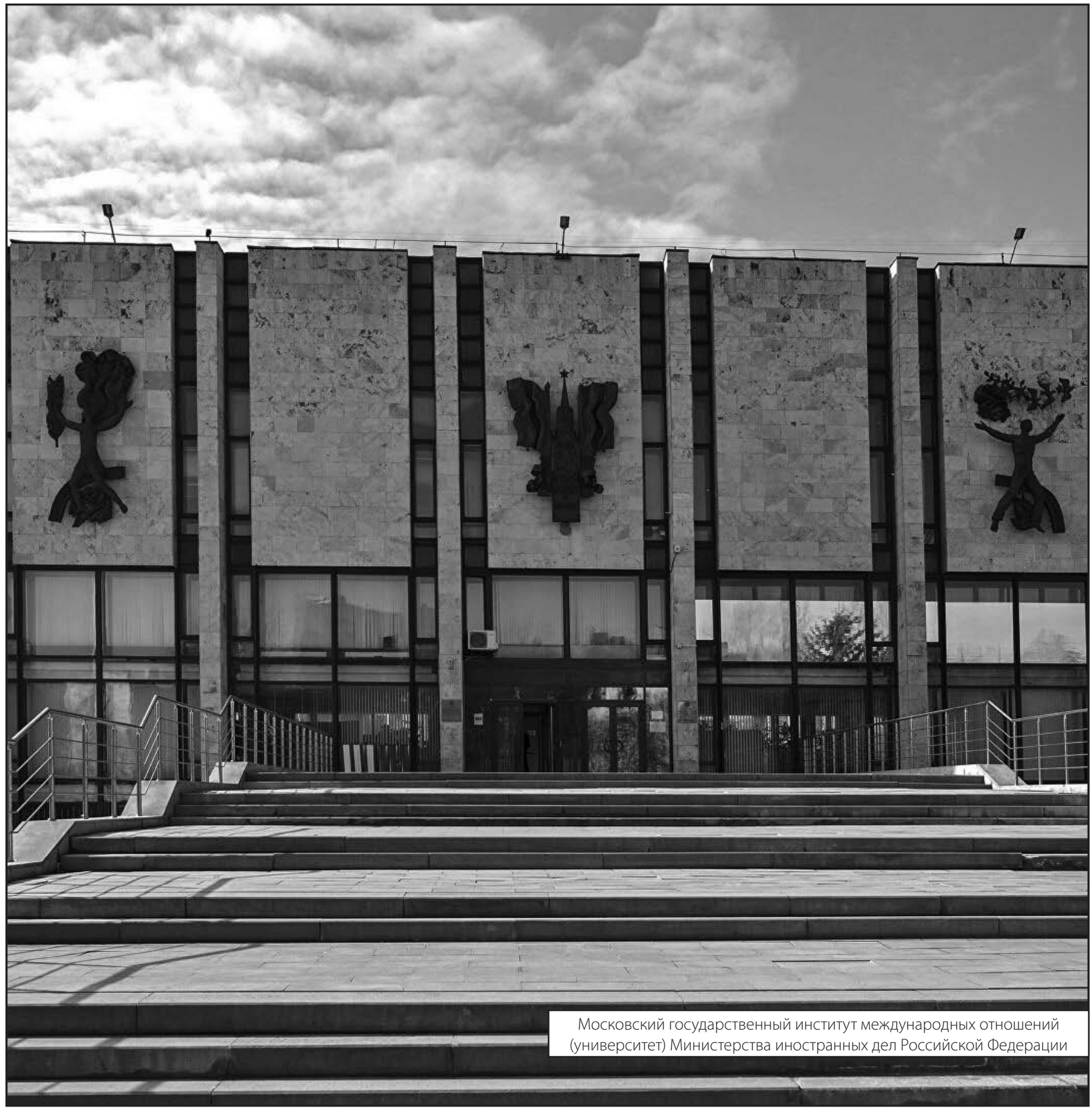

